\title{
Studies on Morphological and Thermal Properties of Low Density Polyethylene/Maize Cob Ash Particulate Composite.
}

\author{
Chike V. Chira, Anthony I. Obi, Danjuma S. Yawas, David O. Obada, \\ Ibraheem A. Samotu \& A. Adesanmi \\ Department of Mechanical Engineering, Ahmadu Bello University, Zaria, Nigeria.
}

\begin{abstract}
A major problem of reinforced composites is that the interfaces between the fiber and matrix become a limiting factor in improving mechanical properties. The effects of reinforcement on the thermal and morphological characteristics of the low density polyethylene/maize cob ash particulate composite are studied. Morphology of the maize cob ash by scanning electron microscope (SEM) with energy dispersive system (EDS), revealed that the maize ash particles were solid in nature but irregular in size. The EDS scan reveal that the microstructure for the maize cob ash consists of only carbon, silicon, oxygen, aluminium and calcium $(\mathrm{C}, \mathrm{Si}, \mathrm{O}, \mathrm{Al}, \mathrm{Ca})$. The incorporation of the maize cob ash particles into the recycled low density polyethylene (RLDPE) matrix increased the thermal decomposition temperatures and the residual yields of RLDPE/MCSp composite, and this enhancing effect was more pronounced at higher heating rate. This result indicated that the presence of maize cob particles (MCSp) could lead to the stabilization of RLDPE, resulting in the enhancement of the thermal stability of RLDPE/MCSp composite.
\end{abstract}

Keywords: - Composite, Maize cob ash, Microstructure, Thermal Stability

\section{INTRODUCTION.}

These interfaces between the fiber and the matrix in short-fiber composites play a critical role and, in many cases, become a limiting factor in improving such mechanical properties as strength and toughness of the composites [1-4]. However, with a strong interface it is difficult to relieve fiber stress concentration in front of an approaching crack; and such stress concentration can result in fiber breakage [5,6]. This effect is particularly severe for ceramic matrix composites, because of their low matrix toughness and lack of plasticity. Even for a composite with a highly ductile matrix, such as plastics, too strong an interface may still cause successive adjacent fiber breakage and subsequently reduce composite toughness [1,6].

Nowadays, there is a great concern about the increasing volume of plastic waste generated in the world, especially in great urban centers. In this scenario, numerous studies have been conducted in order to: (1) Enhance the biodegradability of fossil-fuel-based conventional polymers by blending them with biodegradable natural polymers such as starch or cellulose (2) Mixing with pro-oxidants so that they are more easily degraded; and (3) Isolate and improve microorganisms that can efficiently degrade these polymers[7-10].

Polyolefins are considered bioinert polymers which mean that they are highly resistant to assimilation by microorganisms such as fungi and bacteria. This is expected as the long hydrocarbon chains of these polymers are responsible by the pronounced hydrophobic character. Besides, the addition of antioxidants and stabilizers during their manufacture keeps these materials from atmospheric oxidation. Other structural characteristics such as high molecular weight, high packing density and low surface area make polyolefins non susceptible to biodegradation [11-14].

Low density polyethylene (LDPE) plays a key role in the industry of polyolefins due to its wide range of applications. This polymer has good properties, such as: high flexibility, good processability; excellent resistance to dilute and concentrated acids, alcohols, bases and esters; impact resistance; and dimensional stability[15]. Nevertheless, LDPE waste persists for thousands years after disposal causing a negative environmental impact. Therefore, the introduction of biodegradable polymers or natural fillers in LDPE based materials formulation may be considered as an alternative in the development of more ecofriendly material [15$16]$.

This current research is aimed at studying the effects of the introduction of maize comb ash on the morphology and thermal properties of the composite material. Therefore, the specific objectives of this research are as follows:

i. Examination of the morphology of the developed composite material with increase in Maize cob ash (MCA) loading and,

ii. Study on the thermal stability of the developed composite material with increase in MCA loading. 


\section{MATERIALS AND METHODS.}

Materials and Equipment that was used in this research were-,Maize cob, water sachet (LDPE),Metal mould, hydraulic press, Scanning electron microscope (SEM) and TGA Q50 thermo gravimetric analyzer .

\subsection{Characterization of Maize Cob}

The maize cob was subjected to the following processes before use:-

i. Chemical treatment of the maize cob was done by soaking it in sodium hydroxide solution.

ii. The processing of the maize cob into maize cob particles which involved collection, drying and grinding of the cob to form powder after treatment.

iii. Carbonization of the maize cob powder was done using graphite crucible which was fired in electric resistance furnace at temperature of $1200^{\circ} \mathrm{C}$.

iv. The particle size analysis of the maize cob particles was carried out in accordance with BS1377:1990, the

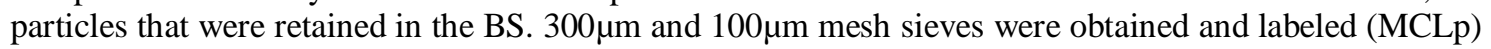
and (MCSp) respectively. The two groups were used separately to reinforce the composite.

\subsection{Sample preparation}

The fabrication of the various composite materials was carried out through the compressive technique. Maize cob ash particle are reinforced with RLDPE. After drying in an oven at $105^{\circ} \mathrm{C}$, the maize cob ash particles and the RLDPE was compounded in a two roll mill at a temperature of $130^{\circ} \mathrm{C}$, into a homogenous mixture. The composites production was carried out on an electrical heated hydraulic press. The mixtures were placed in a rectangular mould with a size of $350 \mathrm{~mm}$ by $350 \mathrm{~mm}$. The composites were pressed to a thickness of $4 \mathrm{~mm}$. At the end of press cycle the composites was removed from the press for cooling. 5-30wt\% of maize cob ash particles was used with interval of $5 \mathrm{wt} \%$. Five $\mathrm{d}$ i f f e $\mathrm{r}$ e $\mathrm{n} t$ types of composites were fabricated with two different maize cob particles (MCS and MCL).

\subsection{Microstructural Analysis}

The scanning electron microscope (SEM) JEOLJSM-6480LV was used to identify the surface morphology of the maize cob ash and composite samples. The samples were washed, cleaned thoroughly; airdried and are coated with 100A thick platinum JEOL sputter ion coater and observed on the SEM at $20 \mathrm{kV}$. The digitized images were recorded.

\subsection{Thermal Properties}

Thermal decomposition was observed in terms of global mass loss by using a TA Instrument TGA Q50 thermo gravimetric analyzer. This apparatus detects the mass loss with a resolution of 0.1 as a function of temperature. The samples were evenly and loosely distributed in an open sample pan of $7.0 \mathrm{~mm}$ diameter and $4.0 \mathrm{~mm}$ deep with an initial sample amount of 6-10 mg. The temperature change was controlled from room temperature $\left(25 \pm 3^{\circ} \mathrm{C}\right)$ to $700^{\circ} \mathrm{C}$ at a heating rate $10^{\circ} \mathrm{C} / \mathrm{min}$.

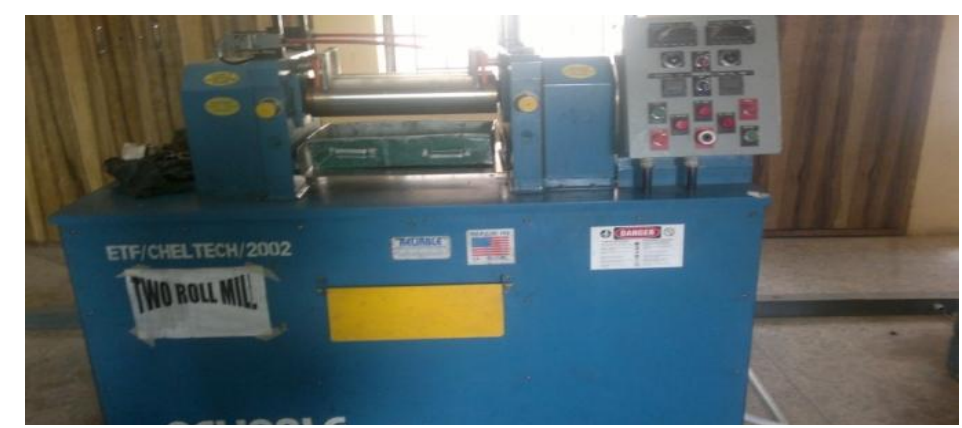

Figure 1: A pictorial view of the two roll mill (NILEST).

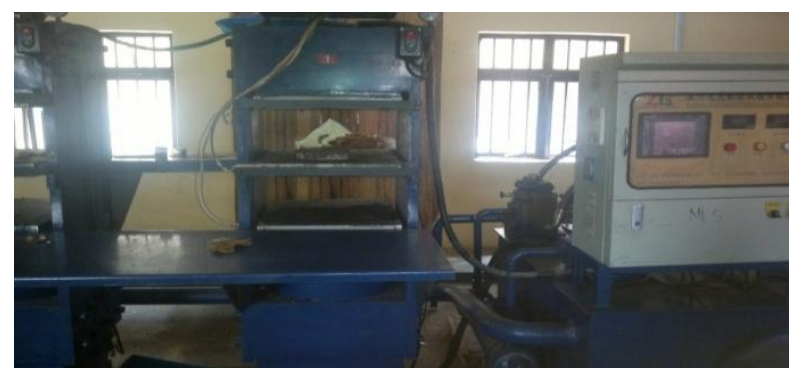

Figure 2: A pictorial view of the Pressing machine (NILEST). 


\section{RESULTS AND DISCUSSION.}

\subsection{Surface Morphology of the Maize cob ash and the Developed Composites}

Morphology of the maize cob ash by Scanning Electron Microscope with Energy dispersive system (EDS), revealed that the maize ash particles were solid in nature but irregular in size. The EDS scan in rectangle label reveal that the microstructure for the maize cod ash consists of only $\mathrm{C}, \mathrm{Si}, \mathrm{O}, \mathrm{Al}, \mathrm{Ca}$, (see Plate 1). Chemical analysis by EDS show that. $\mathrm{SiO}_{2}$, carbon, $\mathrm{CaO}$ were found to be major constituents. Silicon dioxide, carbon, alumina are known to be among the hardest substances. Some other oxides viz. $\mathrm{MgO}, \mathrm{K}_{2} \mathrm{O}$, $\mathrm{Na}_{2} \mathrm{O}$ was also found to be present in traces. The presence of hard elements like $\mathrm{SiO}_{2}, \mathrm{Al}_{2} \mathrm{O}_{3}$ suggested maize cob ash to be used as particulate reinforcement in RLDPE.

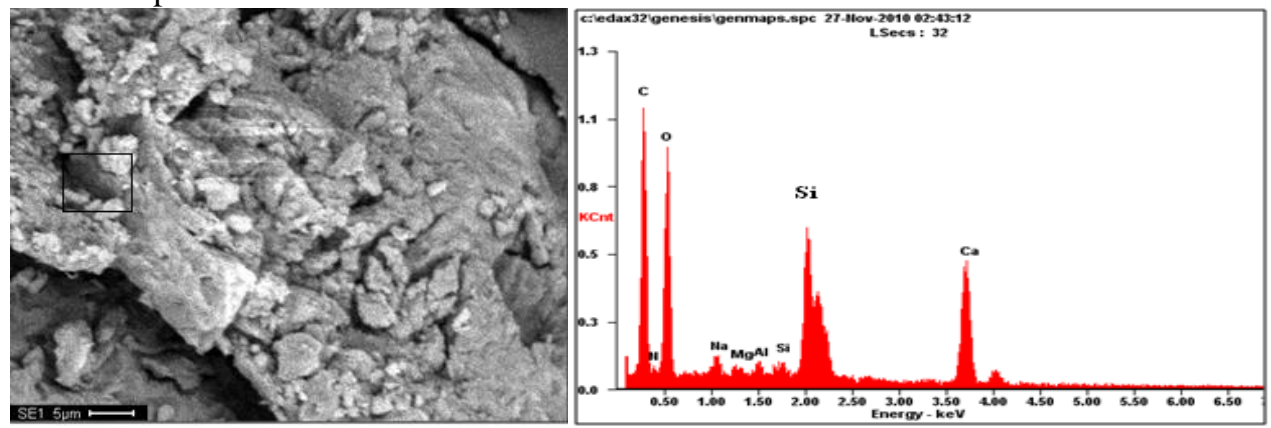

Plate 1: SEM/EDS of the microstructure of the maize ash particles

The microstructure of the RLDPE matrix reveals chain of lamellae and interlammeller amorphous structure with linear boundaries between adjacent spherulites boundaries. From the EDS spectrum it can be clearly seen that the functional group of the RLDPE was revealed. (see plate 2).
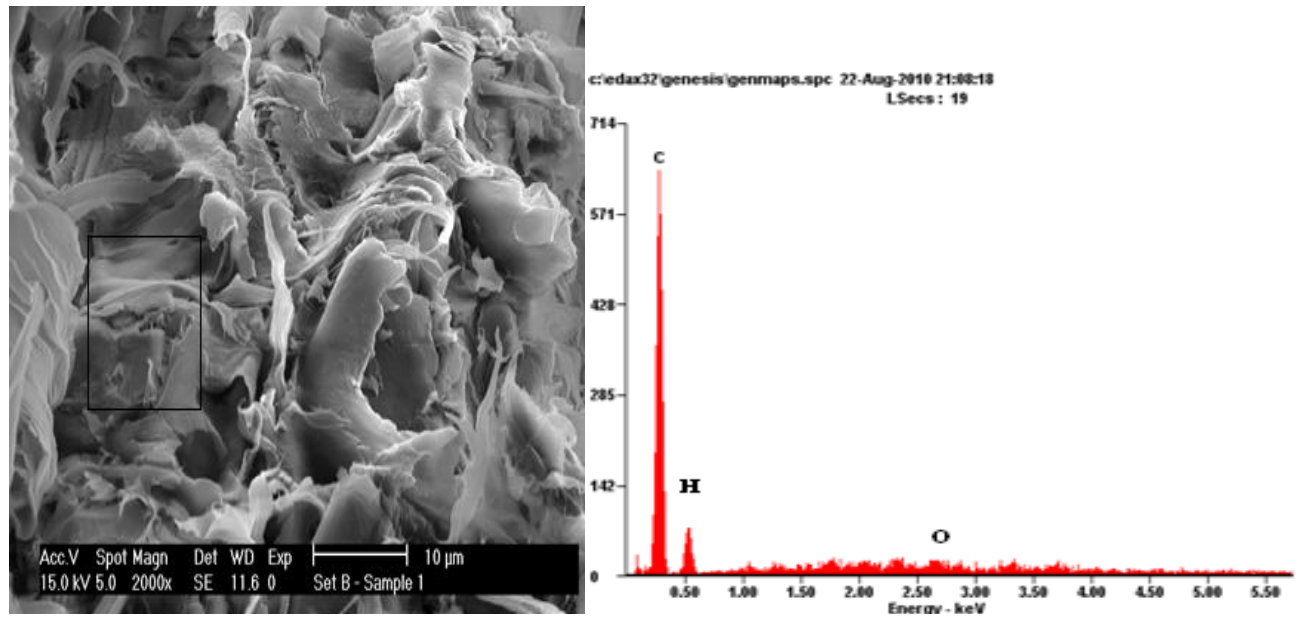

Plate 2: SEM/EDS of the microstructure of the RLDPE

The structures in (plates 3-8) clearly show that when the maize cob ash was added to the RLDPE, morphological change in structure took place. Morphological analysis using SEM clearly shows difference in the morphology of the RLDPE and its composites.

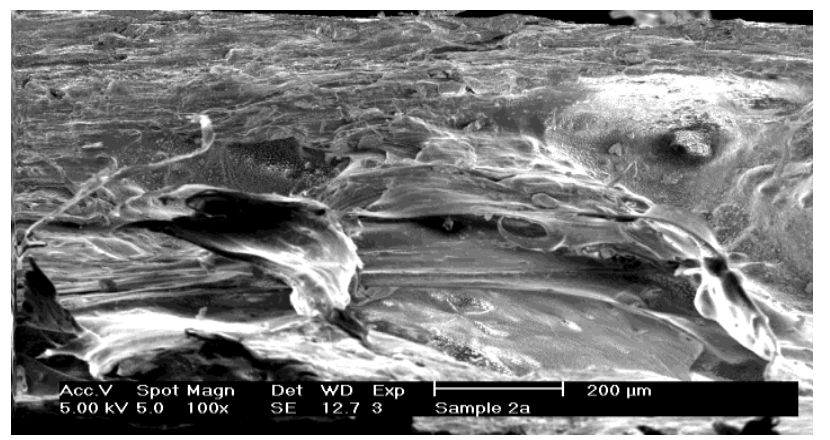

Plate 3: SEM of the microstructure of the Composite with $5 \mathrm{wt} \%$ MCLp 


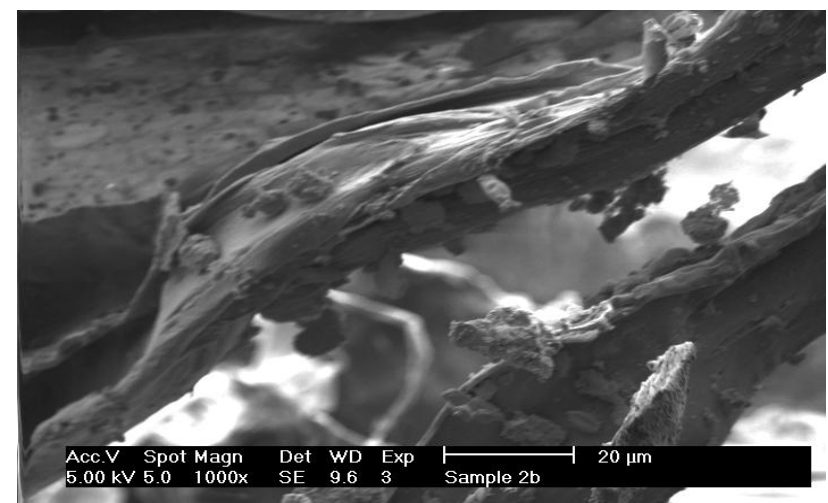

Plate 4: SEM of the microstructure of the Composite with $5 \mathrm{wt} \% \mathrm{MCS}$

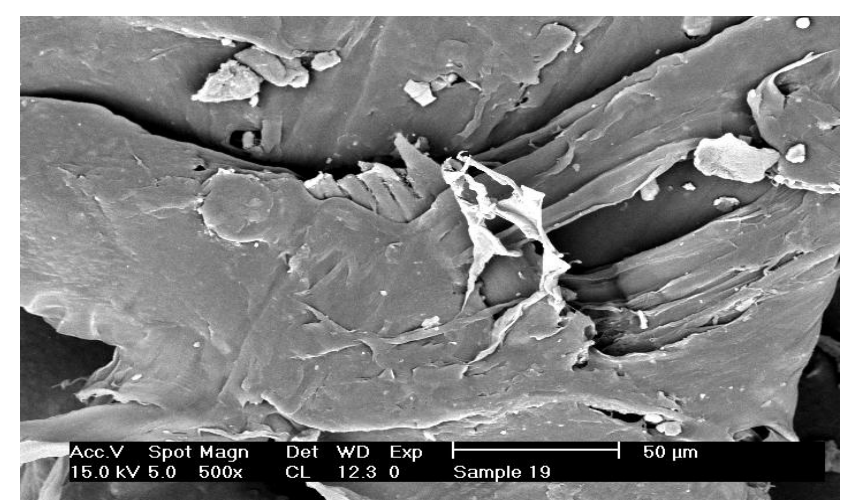

Plate 5: SEM of the microstructure of the Composite with 15wt\% MCLp

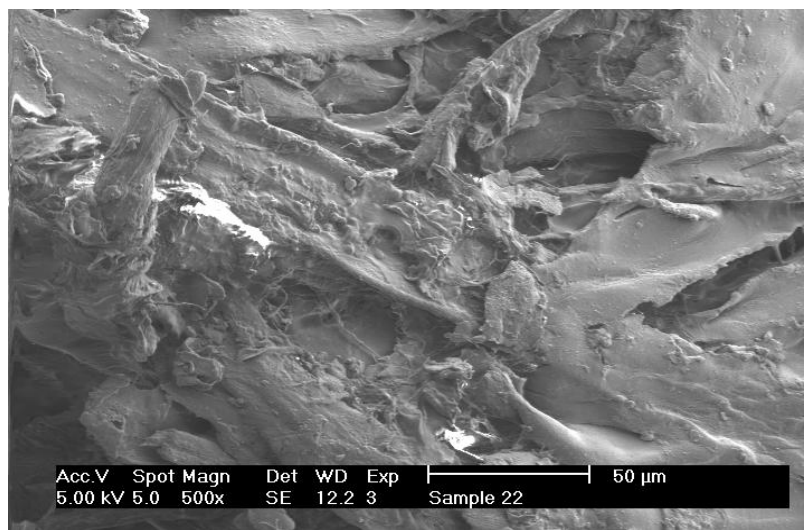

Plate 6: SEM of the microstructure of the Composite with 15 wt $\%$ MCSp
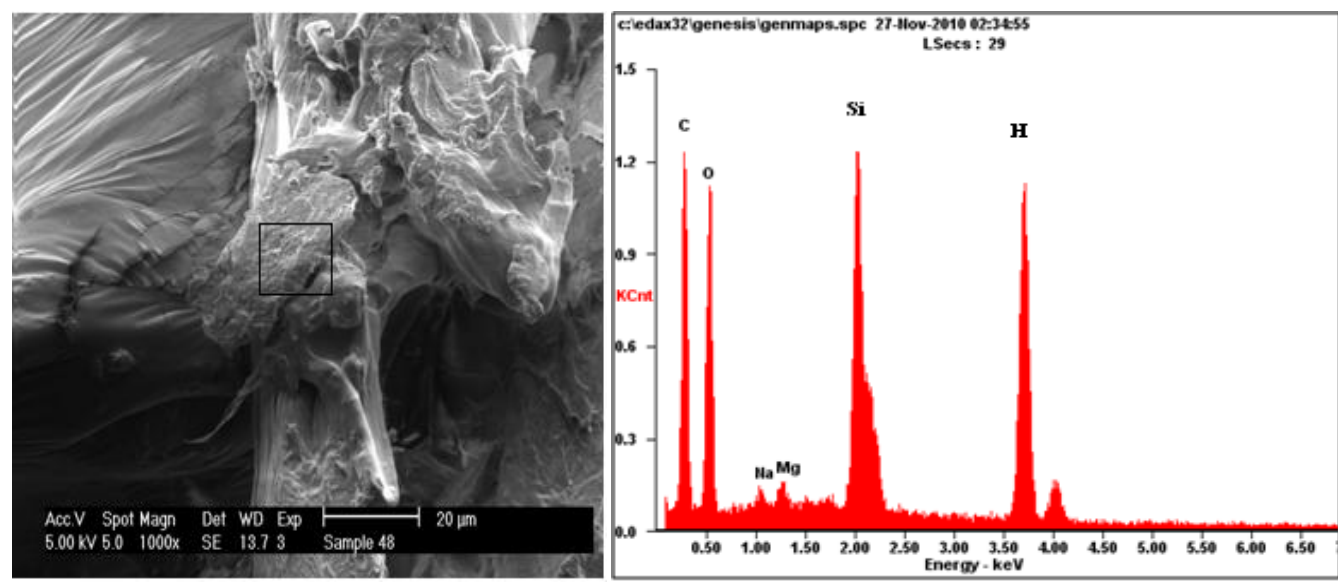

Plate 7: SEM/EDS of the microstructure of the Composite with 30wt\%MCLp 

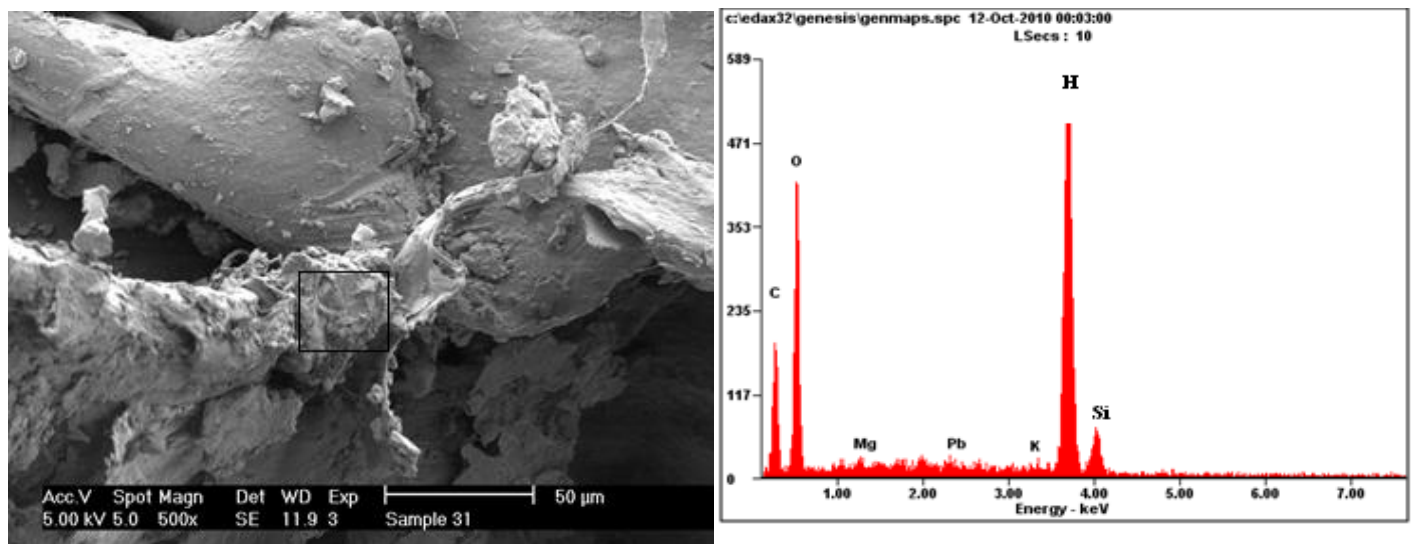

Plate 8: SEM/EDS of the microstructure of the Composite with $30 \mathrm{wt} \% \mathrm{MCSp}$

The microstructure reveals that there are small discontinuities and a reasonably uniform distribution of particles and the RLDPE. The particles phase is shown as white phase, while the resin phase is dark. The maize cob ash particles are embedded within the amorphous matrix composed of randomly distributed planar boundaries. The surface of the agro-waste particles is smooth indicating that the compatibility between particles and the RLDPE was good. It can be seen that the agro-waste particles are not detached from the RLDPE surface as the weight fraction of maize cob particles increased in the RLDPE.This is due to good interfacial bonding between the polymer and the particles.

\subsection{Thermal behavior}

TGA/DTA curves (see Figures 3-4) of the thermal decomposition for RLDPE and the RLDPE/MCSp composite exhibit only one dominant decline of the residual weight.

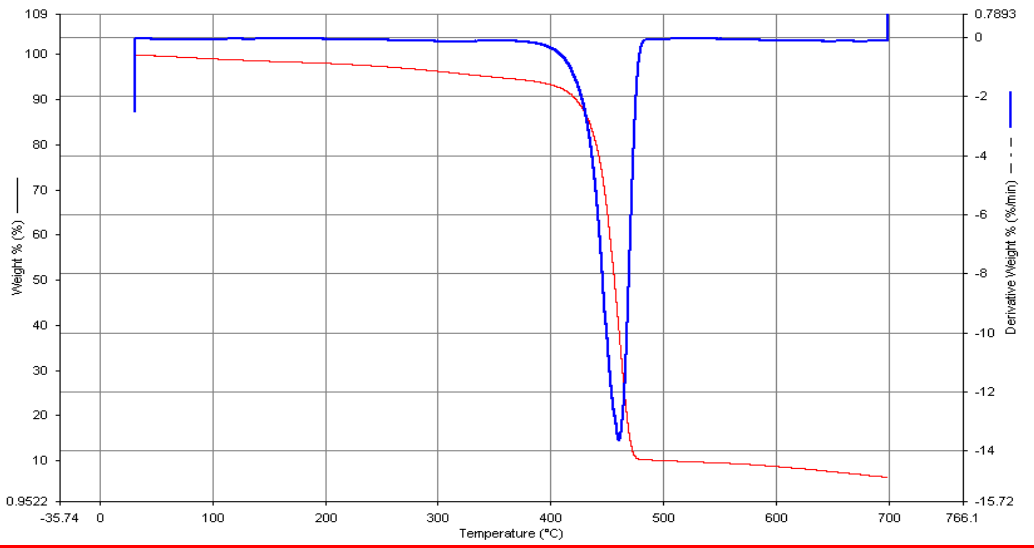

Figure 3: DTA/TGA analysis of the RLDPE at heating rate of $10 \mathrm{~min} /{ }^{\circ} \mathrm{C}$

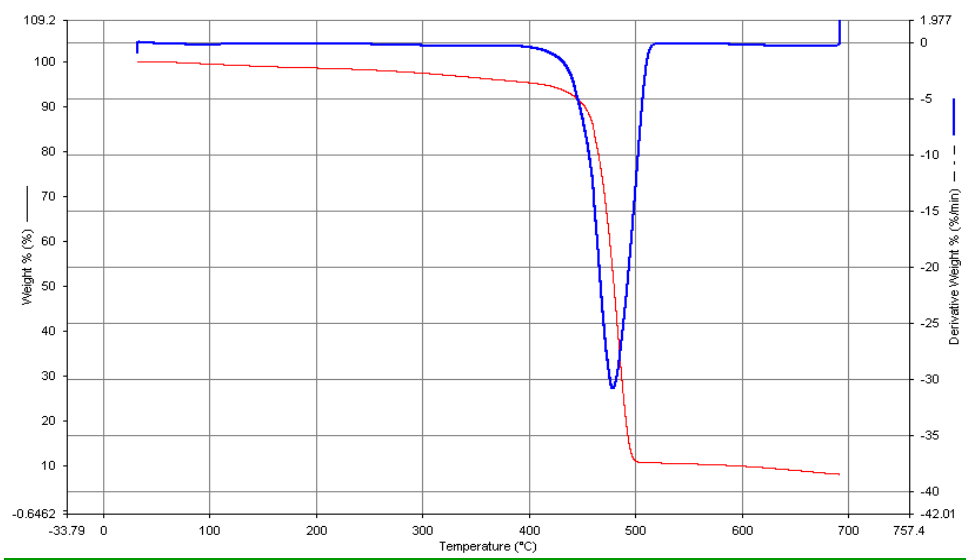

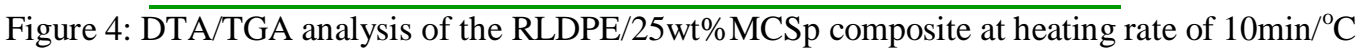


As shown in Figures 3-4, the incorporation of the MCSP particles into the RLDPE matrix increased the thermal decomposition temperatures and the residual yields of RLDPE/MCSp composite, and this enhancing effect was more pronounced at higher heating rate. This result indicated that the presence of maize cob particles (MCSp) could lead to the stabilization of RLDPE, resulting in the enhancement of the thermal stability of RLDPE/MCSp composite.

\section{CONCLUSION}

This work shows the successful fabrication of RLDPE and the maize cob ash particles composite by compounding and compression moulding. The uniform distribution of the maize cob ash particles in the microstructure of the polymer composites could be a major factor responsible for the improvement in the mechanical properties. The incorporated maize cob ash particles play a crucial role in improving the thermal stability by acting as effective physical barriers against the thermal decomposition in the polymer composite.

\section{REFERENCES}

[1] A. Crasto, S. H. Own, and R. V. Subramanian, Composite Interfaces , H. Ishida and J. L.Koenig, eds., (New York, NY: Elsevier Science Publishers, 1986), 133.

[2] M. Fishkis, J. R. Yeh, and K. Wefers, J. Materials Science, 29 (1994) 110.

[3] E. A. Feest, Composites, 25 (1994), 75.

[4] S. M. Kunz, K. Chia, C. H. McMurtry, and W. D. G. Boecker, Composite Applications, T. J. Drozda, ed.,(Dearborn, Michigan: Society of manufacture Engineers, 1989), 38.

[5] E. Yasuda, T. Akatsu, Y. Tanabe, and Y. Matsuo, Composite Materials, A. T. Benedetto,L. Nicolais, and R. Watanabe, eds., (New York, NY: Elsevier Science Publishers, 1992) 167.

[6] T. Norita, J. Matsui, and H. S. Matsuda, Composite Interfaces , H. Ishida and J. L. Koenig,eds., (New York, NY: Elsevier Science Publishers, 1986) 123.

[7] W. Dziadur and A.Tabor, The effect of wood filler behavior on structure and fracture of polyethylene. Journal of Achievements in Materials and Manufacturing Engineering. 2006; 17(1-2):53-56.

[8] D.S Rosa, F. Gaboardi, C.G.F Guedes and M.R Calil. Influence of oxidized polyethylene wax (OPW) on the mechanical, thermal, morphological and biodegradation properties of PHB/LDPE blends. Journal of Materials and Science. 2007; 42:8093-8100. http://dx.doi.org/10.1007/s10853-007-1701-z

[9] J. Arutchelvi, A. Arkatkar, M. Doble, S. Bhaduri and P.S Uppara . Biodegradation of polyethylene and polypropylene. Indian Journal of Biotechnology. 2008; 7:9-22.

[10] S.M Martelli, E.G Fernandes and E. Chiellini, Thermal analysis of soil buried oxo-biodegradable polyethylene based blends. Journal of Thermal Analysis and Calorimetry. 2011; 5(3):333-339.

[11] S.M Martelli, Environmentally compatible polymeric blends and composites based on oxo-biodegradable polyethylene. [Dissertation]. Pisa: University of Pisa; 2011.

[12] M.B Falcone, J.A.M, Agnelli and L.I.L.Faria. Panorama setorial e perspectivas na área de polímeros biodegradáveis. Polímeros. 2007; 17(1):5-9. http://dx.doi.org/10.1590/S0104- 14282007000100005

[13] P.B Shah, S. Bandopadhyay and J.R Bellare. Environmentally degradable starch filled low density polyethylene. Polymer Degradation and Stability. 1995; 47:165-173. http://dx.doi. org/10.1016/01413910 (94)00088-P

[14] F.M.B Coutinho, Mel lo IL and Santa Mar ia LC. Polietileno: Principais tipos, propriedades e aplicações. Polímeros. 2003; 13(1):1-13. http://dx.doi.org/10.1590/S0104- 14282003000100005

[15] B. Nowak, J. Pajak and J. Karcz. Biodegradation of Pre- Aged Modified Polyethylene Films. In: Scanning Electron Microscopy 32: Structure and properties of biodegradable polymer composites material. Vlascheslaw Kazmiruk; 2012. p. 643-670. Available from: <http:// www.intechopem.com./ books/scanning-electron-microscopy/biodegradation/of-pre-aged-modified-polyethylene-films>. Access in: $20 / 07 / 2013$

[16] K. Hamad, M. Kaseem and F. Deri. Melt rheology of poly (lactic acid)/low density polyethylene polymer blends. Advances in Chemical Engineering and Science. 2011;1:208-214. http:// dx.doi.org/10.4236/aces.2011.14030. 